\title{
Mechanism of Action of Gemfibrozil on Lipoprotein Metabolism
}

\author{
Keijiro Saku, Peter S. Gartside, Barbara A. Hynd, and Moti L. Kashyap \\ Apolipoprotein Research Laboratory, Lipid Research Center, Department of Internal Medicine, and the General Clinical
}

Research Center, University of Cincinnati Medical Center, Cincinnati, Ohio 45267

\begin{abstract}
Gemfibrozil is a potent lipid regulating drug whose major effects are to increase plasma high density lipoproteins (HDL) and to decrease plasma triglycerides (TG) in a wide variety of primary and secondary dyslipoproteinemias. Its mechanism of action is not clear. Six patients with primary familial endogenous hypertriglyceridemia with fasting chylomicronemia (type $V$ lipoprotein phenotype) with concurrent subnormal HDL cholesterol levels (HDL deficiency) were treated initially by diet and once stabilized, were given gemfibrozil $(1,200 \mathrm{mg} / \mathrm{d})$. Each patient was admitted to the Clinical Research Center with metabolic kitchen facilities, for investigation of HDL and TG metabolism immediately before and after 8 wk of gemfibrozil treatment. Gemfibrozil significantly increased plasma HDL cholesterol, apolipoprotein (apo) AI, and apo AII by 36\%, $29 \%$, and $38 \%$ from base line, respectively. Plasma TG decreased by $54 \%$. Kinetics of apo AI and apo AII metabolism were assessed by analysis of the specific radioactivity decay curves after injection of autologous HDL labeled with ${ }^{125} \mathbf{I}$. Gemfibrozil increased synthetic rates of apo AI and apo AII by $27 \%$ and $34 \%$, respectively, without changing the fractional catabolic rates. Stimulation of apo AI and apo AII synthesis by gemfibrozil was associated with the appearance in plasma of smaller (and heavier) HDL particles as assessed by gradient gel electrophoresis and HDL composition. Postheparin extrahepatic lipoprotein lipase activity increased significantly by $25 \%$ after gemfibrozil, and was associated with the appearance in plasma of smaller very low density lipoprotein particles whose apo CIII:CII ratio was decreased.
\end{abstract}

These data suggest that gemfibrozil increases plasma HDL levels by stimulating their synthesis. Increased transport (turnover) of HDL induced by gemfibrozil may be significant in increasing tissue cholesterol removal in these patients.

\section{Introduction}

Gemfibrozil is a widely used potent lipid regulating drug. Its major action is to lower plasma triglyceride (TG) ${ }^{1}$-rich lipo-

Part of this work was presented at the Eighth International Symposium on Drugs Affecting Lipid Metabolism, Philadelphia, PA, 1983.

Address correspondence to Dr. Kashyap, University of Cincinnati Medical Center, K-Pavilion, Mail Location 540, Cincinnati, OH 45267.

Received for publication 30 May 1984 and in revised form 20 November 1984.

1. Abbreviations used in this paper: apo, apolipoprotein; apo AI, AII, B, CII, and CIII, apolipoproteins AI, AII, B, CII, and CIII; CE,

J. Clin. Invest.

(c) The American Society for Clinical Investigation, Inc.

0021-9738/85/05/1702/11 $\$ 1.00$

Volume 75, May 1985, 1702-1712 proteins and to increase high density lipoproteins (HDL) in a variety of primary and secondary (e.g., diabetes mellitus, renal disease) dyslipoproteinemias including endogenous hypertriglyceridemia with and without chylomicronemia (types $\mathrm{V}$ and IV lipoprotein phenotypes, respectively), dysbetalipoproteinemia (type III lipoprotein phenotype), and combined hyperlipidemia (type IIB lipoprotein phenotype) (1-10). Gemfibrozil also lowers low density lipoprotein (LDL) cholesterol to a lesser extent than plasma very low density lipoprotein (VLDL) and TG, and its effect on LDL becomes more pronounced on long-term treatment (1-4). Despite demonstration of its efficacy and relative lack of toxicity so far in patients treated for dyslipoproteinemias, its mechanism of action is not clear. Available evidence indicates that gemfibrozil decreases VLDL apolipoprotein (apo) B and VLDL TG synthesis $(11,12)$. The mechanism by which it increases plasma HDL is unknown. Theoretically, this effect can be achieved by either decreased removal or by increased synthesis of HDL. Since HDL are thought to be important in reverse cholesterol transport (1315), knowledge regarding the mechanism(s) by which drugs increase HDL becomes important. Stimulation of HDL synthesis (and therefore transport) would be associated with increased transport of cholesterol, assuming that HDL was involved in the efflux of cholesterol from tissues to plasma for excretion. Drugs that elevate plasma HDL by decreasing HDL removal rate may not be expected, theoretically, to result in net efflux of body tissue cholesterol. These considerations have important implications in our understanding of basic mechanisms by which lipid regulating drugs may influence the atherosclerotic process. An increase in the clinical usage of such drugs is expected in view of recent clinical and coronary angiographic studies that have demonstrated reduction in coronary disease risk and lack of coronary atherosclerosis progression, respectively, by plasma lipid regulation (16-19).

The aims of this research study were $(a)$ to determine whether gemfibrozil alters synthetic or removal rates of HDL by measuring kinetic parameters (turnover) of the major proteins of HDL, i.e., apo AI and apo AII in patients with HDL deficiency associated with familial hypertriglyceridemia; (b) to determine whether it stimulates lipoprotein lipase and/ or decreases the ratio of apo CIII:CII in TG rich lipoproteinsfactors that decrease plasma TG; and (c) to assess the effects of gemfibrozil on the size and composition of HDL and TG rich lipoproteins.

esterified cholesterol; CRC, Clinical Research Center; DBW, desirable body weight; FC, free cholesterol; FCR, fractional catabolic rate(s); GGE, gradient gel electrophoresis; HDL-C, high density lipoprotein cholesterol; LDL-C, low density lipoprotein cholesterol; LPL, extra hepatic lipoprotein lipase; PL, phospholipid; SR, synthetic rate; TC, total cholesterol; TG, triglyceride; TRL, triglyceride-rich lipoproteins; $\mathrm{Vi}$, initial catabolic rate. 


\section{Methods}

\section{Patients}

Six patients selected here were males between 48 and 64 yr old having primary familial endogenous hypertriglyceridemia with fasting chylomicronemia (type $\mathrm{V}$ lipoprotein phenotype) and subnormal $(<10$ th percentile of reference values [20]) HDL cholesterol (HDL-C). The age, sex, weight, height, percent of desirable body weight (DBW), plasma lipid, and lipoprotein cholesterol values shown in Table I are mean values in the evaluation period (weeks $0-4$ ) on an outpatient basis. All subjects had no past history of angina pectoris or myocardial infarction, hypertension, and hepatic, renal, thyroid function were within normal limits by physical and appropriate biochemical examinations. Subject no. 1 (R.D.) was taking diazepam, three times a day, $2.5 \mathrm{mg}$ diphenhydramine hydrochloride $25 \mathrm{mg}$, every hour; patient no. 2 (E.B.) took ergotamine tartrate and caffeine for migraine only about once every $3 \mathrm{wk}$. The remainder received no medications.

\section{Study protocol}

Recruitment of patients and criteria for exclusion. These studies were carried out in the inpatient and outpatient Clinical Research Center (CRC) facilities at the University of Cincinnati Medical Center. Subjects selected for this study came from a large population of previously characterized or newly referred patients to the Lipid Clinic and were followed closely by one of us. All gave written informed consent that was approved by the Committee on Human Research of the University of Cincinnati Medical Center. Lipoprotein phenotyping was according to the Lipid Research Clinic criteria (21). Family studies were performed as far as possible; patients from kindreds with familial combined hyperlipidemia (familial multiple lipoprotein-type hyperlipidemiatypes IIa, IIb, or type IV lipoprotein phenotypes), or patients with sporadic hypertriglyceridemia were excluded. In each selected patient, at least one blood relative had hypertriglyceridemia. Complete physical and appropriate laboratory examinations were done in the evaluation periods to rule out secondary causes of their hyperlipoproteinemia. All patients recruited also had to have HDL-C $<10$ th percentile and LDL-C $<75$ th percentile of reference values (20). The following state or drug use also constituted exclusion: (a) severe hypertension with persistent systolic pressure $>160 \mathrm{mmHg}$ and/or diastolic pressure $>95 \mathrm{mmHg},(b)$ history of persistent or recurrent life threatening cardiac arrythmia, $(c)$ subjects with cardiac failure defined by clinical criteria and cardiomegaly on a postero-anterior chest X-ray, (d) subjects with a body weight $>120 \%$ of DBW, $(e)$ treated hypothyroidism, $(f)$ use of $\beta$-blockers as antihypertensives or antianginal drugs, and $(g)$ chronic alcoholism.

Protocol after recruitment. After recruitment, the patients were initially treated with a hypocaloric $(1,000-1,200 \mathrm{cal})$ National Institutes of Health type $V$ diet (22) at week 4 , and once stabilized, they were switched to an isocaloric diet for at least 6 wk before the first admission to the CRC. If the patients did not achieve stable weight $( \pm 5 \%$ of body weight for at least 6 wk before week 12), they were put on "hold" position until a stable weight was achieved. Patients whose plasma TG dropped below the 90 th reference percentile on weeks 6,8 , and 10 and whose HDL-C increased above the 10th reference percentile on more than one of these three visits were disqualified. At week 12, each patient was admitted to the CRC for 2 wk (weeks 12-14) to get baseline value of several research studies before gemfibrozil therapy. After these studies were completed in the CRC, gemfibrozil $(600 \mathrm{mg}$ twice daily) was prescribed starting at week 14 . The patients were seen every 2 wk on an outpatient basis. After 8 wk of gemfibrozil treatment (weeks 14-22), each patient was readmitted for the second identical set of inpatient research studies (weeks 22-24).

Protocol in CRC. On the third day of admission to the CRC, $1 \mathrm{U}$ of plasma was obtained from each subject by isovolumetric plasmapheresis, and EDTA, aprotinin, and phenylmethyl sulfonyl fluoride were added (23). Aprotinin and phenylmethyl sulfonyl fluoride were added to prevent proteolysis. Plasma for postheparin lipolytic activity measurement was obtained on the third day of admission. On the fourth day, autologous ${ }^{125} \mathrm{I}-\mathrm{HDL}(25 \mu \mathrm{Ci})$ were injected intravenously and blood samples were obtained for $12 \mathrm{~d}$ to assess kinetic parameters of apo AI and apo AII metabolism. Identical research studies were repeated on the second admission (weeks 22-24).

During their inpatient periods, all patients consumed their meals (National Institutes of Health type $V$ diet [22], Table II) from a special metabolic kitchen to assure that they were in a steady state.

HDL turnover studies subprotocol. Potassium iodide solution (100 $\mathrm{mg}$ daily) was given to prevent uptake of radioiodide by the thyroid gland for $4 \mathrm{~d}$ before injection of sterilized ${ }^{125} \mathrm{I}-\mathrm{HDL}$ and throughout the studies. Neck and thigh radioisotope scanning were performed before and after intravenous injection of labeled HDL to make sure thyroidal iodide uptake was blocked completely by prior administration of potassium iodide. After injection of ${ }^{125}$ I-HDL (weeks 12 and 22), $15 \mathrm{ml}$ of blood was obtained at $10 \mathrm{~min}, 2 \mathrm{~h}, 6 \mathrm{~h}, 12 \mathrm{~h}$, and daily for $12 \mathrm{~d}$. 24 hours' urine was collected daily in bottles containing sodium azide and kept at $4^{\circ} \mathrm{C}$ immediately after each urination.

Drug adherence monitoring. At each outpatient visit, adherence to drug was quantitated by the number of capsules left from the number of capsules issued. The adherence to drug for the six patients studied here was $96.6 \pm 0.8 \%$ (mean \pm SEM).

\section{Analytic methods}

Lipid and lipoprotein analysis. Plasma TG, total cholesterol (TC), and HDL-C were determined by the Lipid Research Clinics method (21). Esterified cholesterol was determined by an enzymatic method (24). Phospholipid-phosphorus was determined by the method of Bartlett

Table I. Clinical Data at Study Entry of Patients with HDL Deficiency Associated with Familial Hypertriglyceridemia*

\begin{tabular}{|c|c|c|c|c|c|c|c|c|c|c|}
\hline Subject & Initials & Age & Sex & Weight & Height & $\begin{array}{l}\text { Percent } \\
\text { of } \\
\text { DBW } \neq\end{array}$ & TG & TC & HDL-C & LDL-C \\
\hline & & & & $k g$ & $\mathrm{~cm}$ & & $m g / d l$ & $m g / d l$ & $m g / d l$ & $m g / d l$ \\
\hline 1 & R.D. & 57 & $\mathbf{M}$ & 74.8 & 180 & 102 & 760 & 181 & 22 & 62 \\
\hline 2 & E.B. & 64 & $\mathbf{M}$ & 77.6 & 188 & 97 & 1,008 & 295 & 20 & 123 \\
\hline 3 & R.T. & 48 & $\mathbf{M}$ & 93.4 & 183 & 115 & 1,196 & 338 & 18 & 91 \\
\hline 4 & R.F. & 54 & $\mathbf{M}$ & 71.2 & 165 & 107 & 594 & 263 & 18 & 106 \\
\hline 5 & M.K. & 49 & $\mathbf{M}$ & 87.5 & 183 & 108 & 1,188 & 257 & 22 & 45 \\
\hline 6 & L.S. & 51 & $\mathbf{M}$ & 68.9 & 168 & 108 & 1,124 & 284 & 29 & 100 \\
\hline Mean \pm SEM & & $54 \pm 2$ & & $78.9 \pm 3.9$ & $178 \pm 4$ & $106 \pm 2$ & $978 \pm 101$ & $270 \pm 21$ & $22 \pm 2$ & $88 \pm 12$ \\
\hline
\end{tabular}

* Type V lipoprotein phenotype. ‡ DBW based on Statistical Bulletin, Metropolitan Life Insurance Co., 40, 1959. 
Table II. Composition of the Diet in CRC Before and After Gemfibrozil*

\begin{tabular}{lll}
\hline & $\begin{array}{l}\text { First admission in CRC } \\
\text { (weeks 12 and 13) }\end{array}$ & $\begin{array}{l}\text { Second admission in CRC } \\
\text { (weeks 22 and 23) }\end{array}$ \\
\hline & Mean \pm SEM & Mean $\pm S E M$ \\
Protein (\%) & $20.5 \pm 0.3$ & $20.0 \pm 0.1$ \\
Fat (\%) & $31.7 \pm 1.2$ & $32.6 \pm 1.1$ \\
Carbohydrate (\%) & $47.8 \pm 1.1$ & $47.5 \pm 1.1$ \\
P/S ratioł & $1.05 \pm 0.02$ & $1.02 \pm 0.03$ \\
Cholesterol $(m g)$ & $376 \pm 8$ & $380 \pm 5$ \\
& & \\
\hline
\end{tabular}

$* n=6$.

$\ddagger$ Polyunsaturated to saturated fat ratio.

(25). Protein was determined by the Lowry method (26), and VLDL protein was determined by a modification (27).

Preparation of ${ }^{125} I-H D L .40 \mathrm{ml}$ of venous blood was obtained 2 wk before the admission date (weeks 10 and 20). HDL $(d=1.09-1.21$ $\mathrm{g} / \mathrm{ml}$ ) was isolated (28) and labeled with ${ }^{125} \mathrm{I}$ according to McFarlane's method (29) using iodine monochloride as modified by Bilheimer et al. (30) and purified as described previously (31). Homogeneity of ${ }^{125} \mathrm{I}-$ HDL was tested by several methods, and the labeling procedure did not alter the properties of HDL as described previously (31). Final specific radioactivity of the ${ }^{125} \mathrm{I}-\mathrm{HDL}$ was $\sim 230 \mathrm{dpm} / \mathrm{ng}$ protein.

Apolipoprotein studies. (a) Total plasma apo AI, apo AII, and apo B: Apo AI, apo AII, and apo B concentrations were determined by electroimmunoassay (32-34). (b) Measurement of specific radioactivity of apo AI and apo AII: the method used was essentially that of Fidge et al. (35). 250-300 $\mu \mathrm{g}$ of apo HDL protein was applied to $15 \%$ polyacrylamide gels containing $0.1 \%$ SDS (36). After $\sim 3 \mathrm{~h}$ of electrophoresis, lines were visible in the positions of apo AI and apo AII. These lines correspond to the anodic side bottom of apo AI and apo AII bands, which were confirmed by a marker gel stained with Coomassie Brilliant Blue and by direct consecutive radioactive scanning of 2-mm slices from another gel. The protein bands were then sliced at 2-3 mm sections, and crushed in $2 \mathrm{ml}$ of $50 \mathrm{mM} \mathrm{NH}_{4} \mathrm{HCO}_{3}, 0.01 \%$ sodium azide, $\mathrm{pH} 8.3$. The mixture was incubated for $24-30 \mathrm{~h}$ at $4^{\circ} \mathrm{C}$ and apolipoproteins were eluated. The purity of eluates was tested by $15 \%$ polyacrylamide gels containing $0.1 \%$ SDS and gel permeation chromatography. A single protein band and single elution peak (radioactivity and protein) were observed when eluates of apo AI and apo AII were separately collected and applied to them. Each gel tube was subjected to low speed centrifugation and the supernate was dialyzed extensively against $50 \mathrm{mM} \mathrm{NH}_{4} \mathrm{HCO}_{3}$ solution. Protein concentration and radioactivity were measured in each sample, and specific radioactivity was obtained. These measurements were performed in duplicate or triplicate for each sample. Deviation of replicate specific radioactivity from their mean was $<4.5 \%$ for apo $\mathrm{AI}$ and $<5.4 \%$ for apo AII. (c) TRL apo CII and apo CIII subspecies and their ratios: TRL $(d<1.02$ $\mathrm{g} / \mathrm{ml}$ ) that was isolated from the plasmapheresis sample (weeks 12 and 22) was lyophilized, delipidated with acetone/ethanol $(1: 1 \mathrm{vol} / \mathrm{vol})$ at $-20^{\circ} \mathrm{C}(23)$, and the TRL urea-soluble protein was subjected to isoelectric focusing as described previously (37).

Postheparin plasma lipolytic activities. Postheparin plasma lipolytic activity was done according to the modified method of Krauss et al. $(38,39)$ and as described previously $(32)$.

Kinetics of lipolysis of TRL. The method used was that of Johnson et al. $(40,41)$ and as previously described $(32,42,43)$.

Gradient gel electrophoresis (GGE) of HDL subfractions. Plasma was adjusted sequentially to a density of $1.063,1.125$, and $1.21 \mathrm{~g} / \mathrm{ml}$, ultracentrifuged, and density cuts of $\mathrm{HDL}_{2}(d=1.063-1.125 \mathrm{~g} / \mathrm{ml})$ and $\mathrm{HDL}_{3}(d=1.125-1.210 \mathrm{~g} / \mathrm{ml})$ were obtained (28). $\mathrm{HDL}_{2}$ and $\mathrm{HDL}_{3}$ were ultracentrifuged again at $d=1.125$ and $d=1.210 \mathrm{~g} / \mathrm{ml}$, respectively, to obtain "washed" HDL subfractions and were dialysed before GGE. The molecular weight and molecular size of $\mathrm{HDL}_{2}$ and $\mathrm{HDL}_{3}$ subfractions were determined by GGE as described by Anderson et al. (44-46).

\section{Calculation of the kinetic parameters of apo AI and apo AII metabolism}

The specific radioactivity decay curves of apo AI and apo AII required three exponentials for adequate fitting. The adequacy of three exponential models for our data of apo AI and apo AII decay curves were tested by means of a test for lack of fit (47). The F statistic was not significant, $P>0.05$. The residence time (the reciprocal of fractional catabolic rate [FCR]) was calculated from the area under the curve according to Schaefer et al. (48). Under steady-state conditions, synthetic rate $(\mathrm{SR})$ was calculated as $(\mathrm{FCR}) \times$ (plasma volume) $\times$ (plasma apo A concentration). Plasma volume was estimated as $4.5 \%$ of body weight and by the radioisotope dilution technique.

${ }^{125}$ I-HDL FCR was also estimated by the Berson and Yalow method (49) using (daily urinary excretion of $\left.{ }^{125} \mathrm{I}\right) /\left(\right.$ plasma ${ }^{125} \mathrm{I}-\mathrm{HDL}$ ) value, which was based on the plasma ${ }^{125}$ I-HDL decay curves.

\section{Statistical analyses}

Correlation coefficients, regression lines, and paired $t$ test for differences between before-drug and after-drug treatment were obtained by standard methods as per Snedecor and Cochran (50). All computations were performed using the SAS software package at the University of Cincinnati Computer Center.

\section{Results}

Plasma lipids, VLDL, LDL, HDL, apo AI, and apo AII. 8 wk of diet therapy (weeks 4-12) had a significant effect on the levels of plasma TG and TC in all patients (Tables I and III). Mean plasma TG and TC were reduced to $47 \%(P<0.01)$ and $80 \%(P<0.02)$ of base line, respectively. However, all patients remained hypertriglyceridemic despite maximum dietary adherence and attaining stable weight ( $<5 \%$ deviation between weeks 6 and 12) by the sixth visit. They proceeded to the drug treatment phase of the study. Table III shows the effects of 8-wk treatment with gemfibrozil on plasma lipids, lipoprotein cholesterol, and apo AI, apo AII, and apo B. Mean plasma TG was reduced to $46 \%$ of base line (weeks 12 and 13) $(P=0.033)$, while mean HDL-C increased by $36 \%(P$ $=0.018)$ of base line. Mean LDL-C rose from a low of $87 \pm 11$ $\mathrm{mg} / \mathrm{dl}$ to within normal range of $115 \pm 15 \mathrm{mg} / \mathrm{dl}$ after gemfibrozil $(P=0.043)$. The effects of gemfibrozil on apolipoproteins were more significant; mean plasma apo AI, apo AII, and apo B increased by $29 \%(P=0.002), 38 \%(P=0.001)$, and $18 \%$ $(P=0.030)$ of base line, respectively. The values shown in Table III are averages of at least five samples selected at even intervals during 2 wk of hospitalization before (weeks 12-14) and during (weeks 22-24) gemfibrozil treatment. The maximum percent deviation from the mean for HDL-C was found to be $3.9 \%$; for apo AI it was $4.2 \%$, and for apo AII it was $3.0 \%$. These were less than the coefficient of variation of the method and indicated that steady state conditions prevailed during the turnover studies. Note that the patients were taking isocaloric diets after they achieved and maintained constant body weight. The changes in body weight before and after $8 \mathrm{wk}$ drug therapy were not significant $(76.7 \pm 4.3$ vs. $74.6 \pm 3.9 \mathrm{~kg}$, mean $\pm S E M)$. The effect of the drug was therefore additional to the effect achieved by diet.

Kinetic parameters of apo AI and apo AII metabolism. Apo AI and apo AII specific radioactivity decay curves were 
Table III. Effects of Gemfibrozil on Plasma Lipid, Lipoprotein Cholesterol, and Apolipoproteins in Studied Subjects

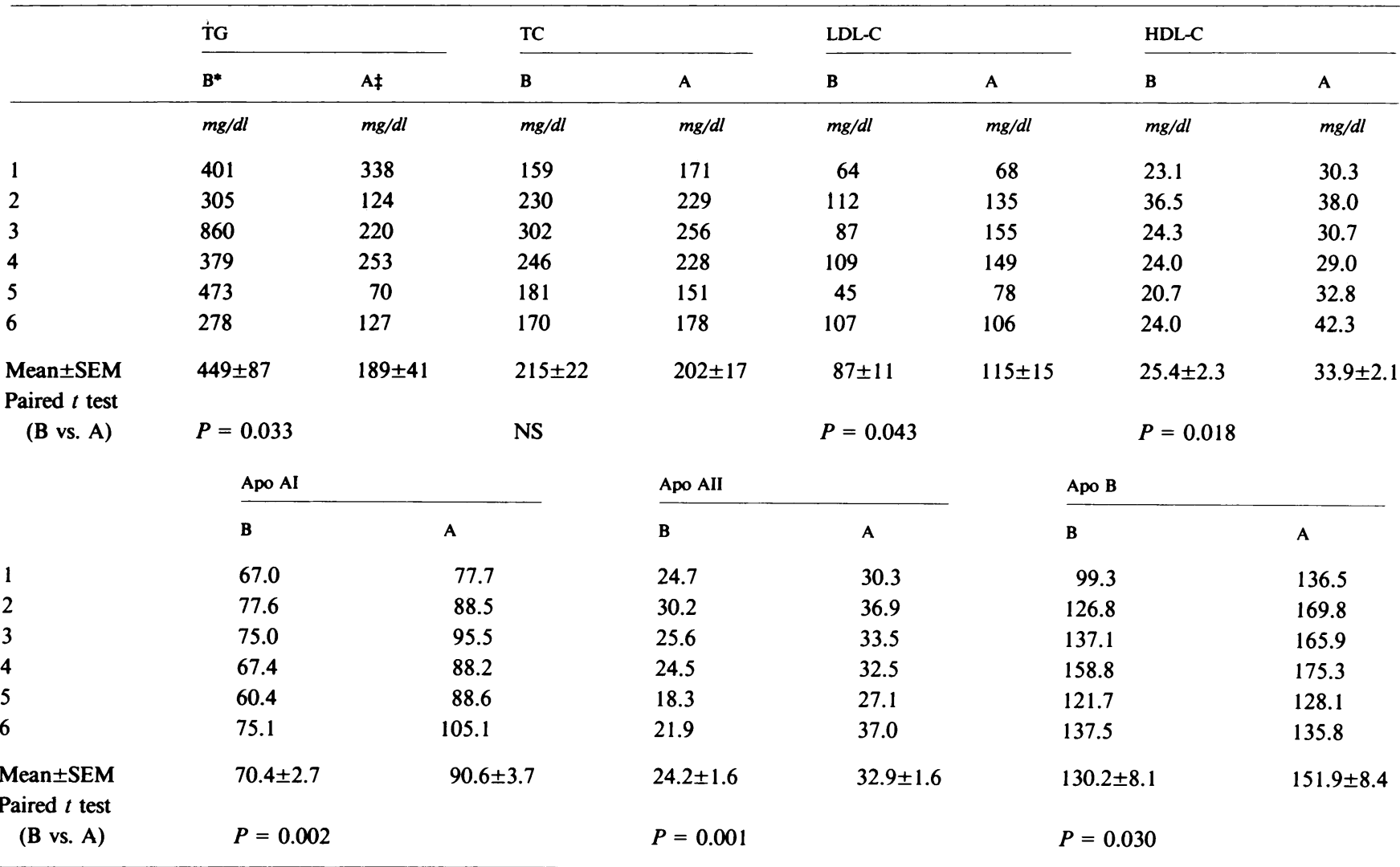

* The average value of first admission in CRC (before gemfibrozil; weeks 12 and 13; Fig. 1). $¥$ The average value of second admission in CRC (after gemfibrozil; weeks 22 and 23; Fig. 1).

plotted against time (Fig. 1), and mathematical analysis of the decay curves are shown in Table IV. Radioisotope scanning of the neck and thigh revealed that $<1 \%$ of administered total radioactivity was sequestered by thyroid gland in all patients, indicating that thyroidal uptake of ${ }^{125}$ I was completely blocked. The kinetic parameters (residence time and FCR) of apo AI and apo AII were not significantly altered by gemfibrozil. FCR of ${ }^{125} \mathrm{I}-\mathrm{HDL}$ measured by the Berson and Yalow method were also similar before and after gemfibrozil $(0.272 \pm 0.013$ vs. $0.252 \pm 0.021 / \mathrm{d}$, respectively). Total mass (M) of apo AI and apo AII and absolute SR for apo AI and apo AII increased after gemfibrozil in every patient studied. The mean SR of apo AI and apo AII increased by $126.8 \pm 5.5 \%$ and $133.6 \pm 5.8 \%$ of base line, respectively. SR of apo AI and apo AII were also calculated using plasma volume obtained by radioisotope dilution technique. The mean SR of apo AI and apo AII increased significantly after gemfibrozil, $10.88 \pm 0.84$ vs. $14.50 \pm 0.52, P=0.01 ; 3.46 \pm 0.27$ vs. $4.87 \pm 0.25, P=0.006$, respectively. (Data were not tabulated).

Composition and particle size of TRL and HDL. The composition of TRL isolated by preparative ultracentrifugation is shown in Table V. The protein content of TRL increased significantly after gemfibrozil $(P=0.036)$. The ratio of core (TG + esterified cholesterol [CE]) to surface (protein + free cholesterol $[\mathrm{FC}]+$ phospholipid $[\mathrm{PL}])$ constituents, an indirect index of particle size (51), showed a reduction but the differences did not achieve statistical significance.

HDL subfractions were separated by preparative ultracen- trifugation and lipid and protein composition were examined (Table V). On gemfibrozil, TG content decreased significantly in $\mathrm{HDL}_{2}(P=0.021)$ and $\mathrm{HDL}_{3}(P=0.001)$, respectively. The particle size index of HDL subfractions showed that $\mathrm{HDL}_{2}$ particle size decreased in all six subjects except one, and the mean size was significantly lower $(P=0.023)$ after gemfibrozil. $\mathrm{HDL}_{3}$ particle size index decreased after gemfibrozil but the difference was not significant.

Isolated HDL subfractions were also subjected to gradient gel electrophoresis (Fig. 2). A major peak (peak I) was seen in density range $1.063-1.125 \mathrm{~g} / \mathrm{ml}$ (Fig. $2 A$ ), while a major peak (peak II) and one or more minor peaks were observed in density range $1.125-1.21 \mathrm{~g} / \mathrm{ml}$ (Fig. $2 B$ ). Molecular diameter and molecular weights of these two major peaks (peak I and peak II) decreased significantly after drug treatment (Table VI).

Apo CII and apo CIII subspecies in TRL. Isolated TRL were also delipidated and apo CII and apo CIII subspecies were separated by analytic isoelectric focusing. The ratios of apo CIII subspecies to apo CII were determined from the densitometric scanning of the stained gels. As detailed in Table VII, apo $\mathrm{CIII}_{0}$ /apo CII, apo $\mathrm{CIII}_{1}$ /apo CII, and total apo CIII/ apo CII ratios were reduced significantly 2 mo after gemfibrozil. However, apo CIII subspecies as percent of total apo CIII (data not shown) were not significantly altered by gemfibrozil treatment in these patients.

Postheparin lipoprotein lipase and hepatic triglyceride lipase activities. Postheparin total, extrahepatic lipoprotein lipase, 
APO AI

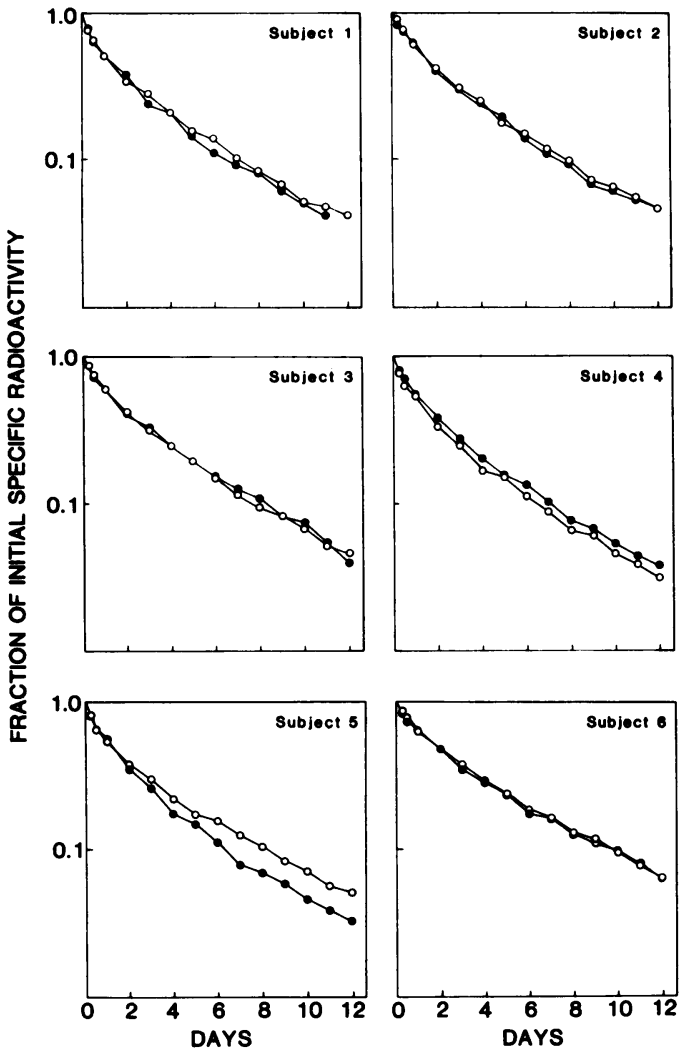

Figure 1. The specific radioactivity decay curves (fraction of initial specific radioactivity) of apo AI (left) and apo AII (right) were plotted on semilogarithmic paper against time for $12 \mathrm{~d}$ before $(-\bullet-)$ and

and hepatic TG lipase activities were measured before and after gemfibrozil treatment (Table VIII). Mean total lipolytic activity on gemfibrozil was $107.0 \pm 3.6 \%$ of base line. Extra hepatic lipoprotein lipase (LPL) increased in all six patients to $124.6 \pm 11.3 \%$ of base line. Hepatic triglyceride lipase did not change significantly.

In vitro lipolysis of TRL by bovine lipoprotein lipase. The property of TRL as a substrate for the enzyme LPL was investigated in vitro $(40,41)$ and the individual lipolysis curves are shown in Fig. 3. The kinetic parameters of lipolysis of TRL with LPL were measured. Initial catabolic rate (Vi) and F30/F0 were significantly decreased after gemfibrozil treatment; $9.45 \pm 0.54$ vs. $7.21 \pm 0.47 \mathrm{U} / \mathrm{min}, P=0.001 ; 4.20 \pm 0.15$ vs. $3.73 \pm 0.07 \mathrm{U}, P=0.034$, respectively (Fig. 3). Both Vi and F30/F0 correlated positively with the particle size index ( $r$ $=0.704, P=0.011$; and $r=0.815, P=0.001$, respectively) but not with the TRL apo CIII/apo CII ratio (Fig. 4). By analysis of covariance, the effect of particle size was corrected and the $\mathrm{Vi}$ and F30/FO were $9.35 \pm 0.28$ vs. $7.31 \pm 0.28 \mathrm{U} / \mathrm{ml}$ and $4.10 \pm 0.1$ vs. $3.83 \pm 0.10 \mathrm{U}$ before and after gemfibrozil, respectively. The decline in $\mathrm{Vi}$ was statistically significant $(P$ $=0.01)$ but not the change in F30/F0 $(P=0.15)$.

\section{Discussion}

The results of this study demonstrate that in patients with HDL deficiency associated with familial hypertriglyceridemia,
APO AII

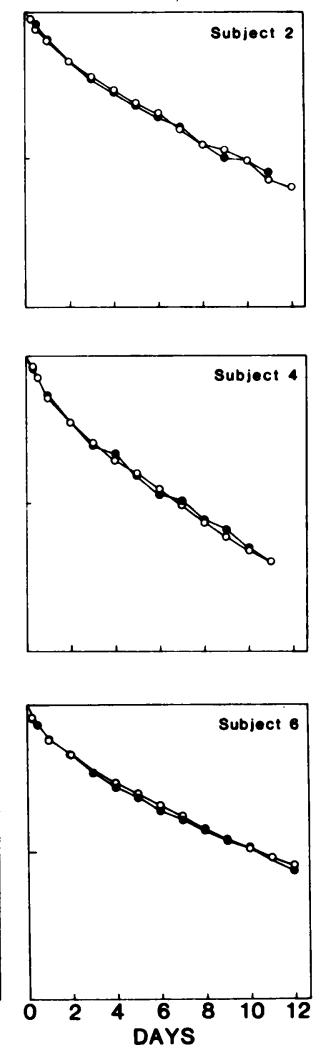

after $(-\circ-)$ gemfibrozil therapy. From these slopes, the kinetic parameters of apo AI, apo AII were calculated. gemfibrozil significantly increased HDL cholesterol, apo AI, and apo AII, and lowered plasma total TG concentration. These findings extend in this group of dyslipidemic patients (type V lipoprotein phenotype) what has previously been found in patients with other lipid disorders (1-10).

Gemfibrozil and HDL metabolism. The concentration of HDL or its apolipoproteins is controlled by synthesis, catabolism, or a combination of both. An insight into the roles of these factors in increasing plasma HDL levels after gemfibrozil is provided by turnover studies of apo AI and apo AII in these patients. These turnover studies were conducted under steadystate conditions in a clinical research center with a rigid control of dietary intake. Validation of this was the observation that maximum variation from mean in HDL-C, apo AI, and apo AII was less than the coefficients of variation of methods used for their quantitation.

The kinetic studies demonstrate that gemfibrozil treatment was associated with a significant increase $(\sim 1.3$-fold $)$ in the synthetic rates of apo AI and apo AII. No alteration in the fractional catabolic rates of these apoproteins was found. These changes were associated with significant reductions in the size of HDL subfractions, which were assessed by gradient gel electrophoresis (Fig. 2 and Table VI) or by using the ratio of core $(\mathrm{TG}+\mathrm{CE})$ to surface (protein $+\mathrm{FC}+\mathrm{PL}$ ) constituents (Table V). These data indicate that gemfibrozil treatment resulted in smaller HDL particles. In concert with this size reduction, a concurrent rise in the concentration of $\mathrm{HDL}$ 
Table IV. Effects of Gemfibrozil on the Kinetic Parameters of Apo AI and Apo AII

\begin{tabular}{|c|c|c|c|c|c|c|c|c|}
\hline & \multicolumn{2}{|l|}{ Total mass* } & \multicolumn{2}{|c|}{ Residence time } & \multicolumn{2}{|c|}{ Fractional catabolic rate } & \multicolumn{2}{|c|}{ Absolute synthetic* rate } \\
\hline & Bł & $A \S$ & B & A & B & A & B & A \\
\hline & $m g$ & $m g$ & $d$ & $d$ & perd & perd & $\mathrm{mg} / \mathrm{kg}$ body wei & \\
\hline \multicolumn{9}{|l|}{$\begin{array}{l}\text { Apo AI } \\
\text { Subject }\end{array}$} \\
\hline 1 & 2,180 & 2,510 & 2.31 & 2.39 & 0.434 & 0.419 & 13.09 & 14.65 \\
\hline 2 & 2,616 & 2,963 & 2.66 & 2.73 & 0.376 & 0.367 & 13.13 & 14.62 \\
\hline 3 & 3,092 & 3,898 & 2.84 & 2.82 & 0.353 & 0.355 & 11.91 & 15.26 \\
\hline 4 & 2,111 & 2,775 & 2.50 & 2.25 & 0.400 & 0.444 & 12.13 & 17.63 \\
\hline 5 & 2,365 & 3,138 & 2.34 & 2.69 & 0.428 & 0.372 & 11.63 & 14.83 \\
\hline 6 & 2,180 & 2,938 & 3.20 & 3.28 & 0.312 & 0.305 & 10.55 & 14.43 \\
\hline Mean \pm SEM & $2,424 \pm 153$ & $3,037 \pm 193$ & $2.64 \pm 0.14$ & $2.69 \pm 0.15$ & $0.384 \pm 0.019$ & $0.377 \pm 0.020$ & $12.07 \pm 0.40$ & $15.24 \pm 0.49$ \\
\hline $\begin{array}{c}\text { Paired } t \text { test } \\
\text { (B vs. A) }\end{array}$ & $P=0.001$ & & NS & & NS & & $P=0.004$ & \\
\hline \multicolumn{9}{|l|}{$\begin{array}{l}\text { Apo AII } \\
\text { Subject }\end{array}$} \\
\hline 1 & 804 & 979 & 2.95 & 2.98 & 0.339 & 0.336 & 3.77 & 4.58 \\
\hline 2 & 1,018 & 1,235 & 3.17 & 3.16 & 0.316 & 0.317 & 4.30 & 5.26 \\
\hline 3 & 1,055 & 1,367 & 2.80 & 2.80 & 0.357 & 0.358 & 4.11 & 5.40 \\
\hline 4 & 767 & 1,022 & 2.38 & 2.38 & 0.420 & 0.421 & 4.63 & 6.16 \\
\hline 5 & 716 & 960 & 2.53 & 2.82 & 0.395 & 0.354 & 3.25 & 4.32 \\
\hline 6 & 636 & 1,034 & 3.17 & 3.34 & 0.315 & 0.299 & 3.10 & 4.98 \\
\hline Mean \pm SEM & $833 \pm 69$ & $1,100 \pm 67$ & $2.83 \pm 0.13$ & $2.91 \pm 0.14$ & $0.357 \pm 0.017$ & $0.348 \pm 0.017$ & $3.86 \pm 0.25$ & $5.12 \pm 0.27$ \\
\hline $\begin{array}{l}\text { Paired } t \text { test } \\
\text { (B vs. A) }\end{array}$ & $P=0.0004$ & & NS & & NS & & $P=0.0006$ & \\
\hline
\end{tabular}

* Based on plasma volume equals $4.5 \%$ of body weight. $\ddagger$ Before gemfibrozil therapy. $\S$ After gemfibrozil therapy.

components (e.g., cholesterol, apo AI, and apo AII) suggests that the number of HDL particles increased per unit plasma volume after gemfibrozil.

Experimental evidence indicates that apo AI and apo AII are synthesized by the intestine and the liver (52-55) into nascent HDL. These primordial HDL particles are thought to result in small HDL particles that probably correspond to the heavier circulating $\mathrm{HDL}_{3}$ subfraction. Some evidence suggests that these particles enlarge during TRL catabolism $(56,57)$.

These considerations do not pinpoint the precise mechanism by which gemfibrozil effected these changes. The reason is that these studies, which describe two steady states, do not conclu- sively show the exact route taken from first steady state to the second. Thus, the findings of increased apo A synthetic rate and plasma concentration of smaller HDL particles after gemfibrozil therapy are compatible with the inference that gemfibrozil's action in raising HDL is by stimulation of apo $\mathrm{AI}$ and apo AII synthesis. Conclusive proof of this may require confirmation by other approaches that were beyond the scope of the current investigation.

Significance of gemfibrozil's action on HDL metabolism. Under steady conditions, the absolute synthetic and catabolic rates (i.e., transport) of a given plasma substance are equal. Thus, gemfibrozil treatment in this study resulted in mean

Table V. Effects of Gemfibrozil on Lipoprotein Composition*

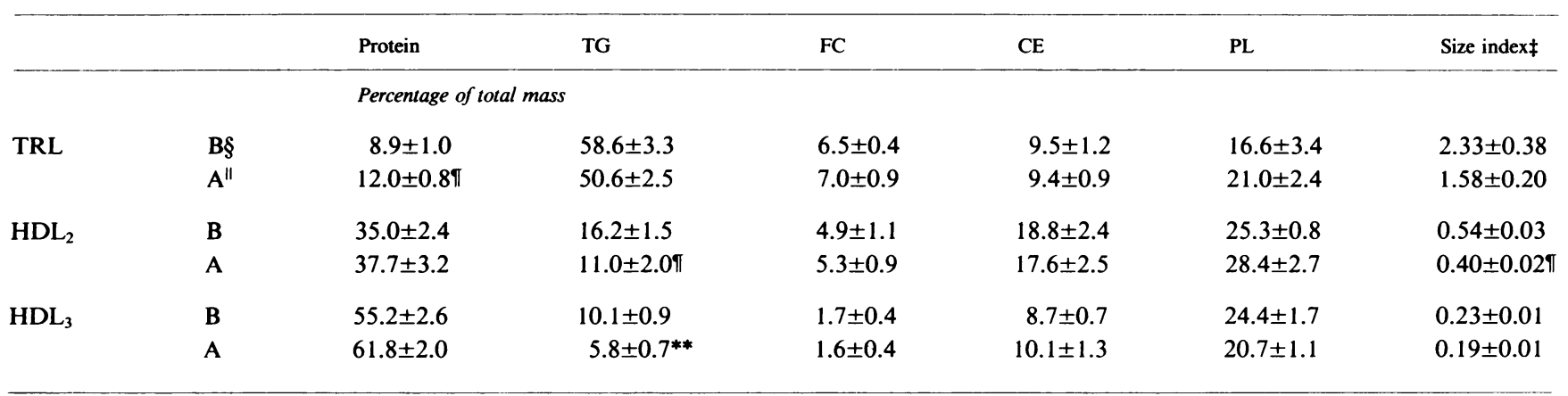

${ }^{*} n=6$, mean \pm SEM. $\ddagger$ Ratio of core $(\mathrm{TG}+\mathrm{CE}$ ) to surface (protein $+\mathrm{FC}+\mathrm{PL}$ ) constituents. $\S$ Before gemfibrozil therapy. "After gemfibrozil therapy. II $P<0.05$, B vs. A. ${ }^{* *} P<0.005$, B vs. A. 

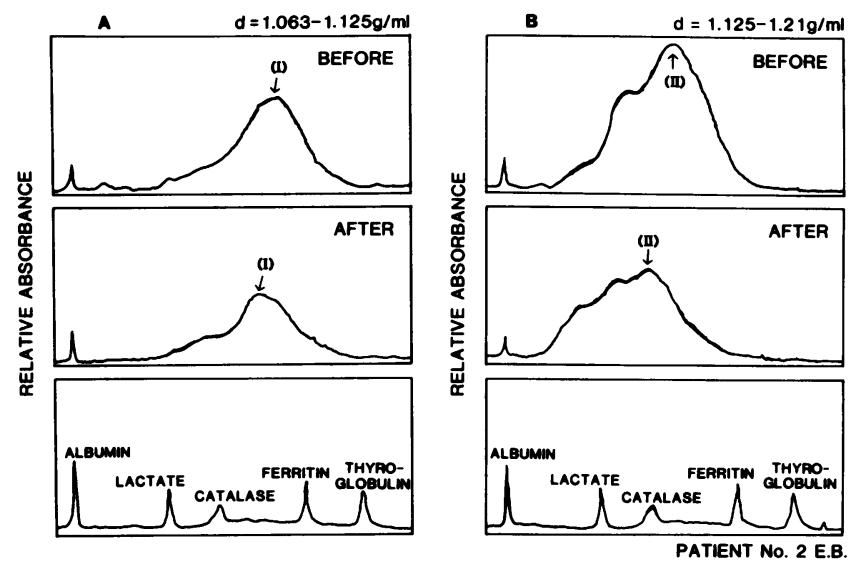

Figure 2. Effects of gemfibrozil on the distribution and size of $\mathrm{HDL}_{2}$ $(A)$ and $\mathrm{HDL}_{3}(B)$ as determined by GGE. Electrophoresis was performed on a Pharmacia Electrophoresis Apparatus (GE-4II) using premade gradient gel (PAA4/30) at $200 \mathrm{~V}$ for $22 \mathrm{~h}$ at $10^{\circ} \mathrm{C}$ in a buffer containing $0.09 \mathrm{M}$ Tris-HCl, $0.08 \mathrm{M}$ borate, $0.01 \%$ EDTA, $0.001 \%$ sodium azide, $\mathrm{pH} 8.35 .60 \mu \mathrm{g}$ of lipoprotein protein were applied to each gel. After electrophoresis, the gels were stained with Coomassie Brilliant Blue, destained, and scanned as described previously (45). The molecular weight and size of peaks obtained by scanning were determined by coelectrophoresis of pure protein standards (using high molecular weight calibration kit, Pharmacia) of known molecular weight and particle size as described by Blanche et al. (46).

increases of $126.8 \%$ and $133.6 \%$ in the absolute catabolic rate of apo AI and apo AII, respectively. Experimental evidence indicates that $\mathrm{HDL}$ is important in reverse cholesterol transport $(13,14)$ and is specifically more important than LDL in the transport of cholesterol to the liver (15). Further, apo AI is important in this process not only in free cholesterol uptake from cells (58), but it also participates in the cholesterol esterification $(59,60)$. Thus, increased apo AI transport can theoretically be associated with increased tissue cholesterol efflux and possibly increased HDL mediated cholesterol removal. Drugs that increase plasma apo AI levels by decreasing its FCR (e.g., nicotinic acid) would not theoretically be expected to be associated with increased body tissue cholesterol removal. The available evidence supports these concepts (61-66). However, in a recent report by Kesaniemi and Grundy (12), gemfibrozil treatment had no effect on sterol balance in a group of hyperlipidemic males who did not have familial type $\mathrm{V}$ dyslipoproteinemia as in this study. One explanation for this could be as follows. Gemfibrozil accelerates VLDL catabolism and the short-term result is increased plasma LDL-C and apo B concentrations. This leads to down-regulation of hepatic LDL receptors, resulting in decreased hepatic uptake
Table VI. Effects of Gemfibrozil on the Molecular Diameter and the Molecular Weight of Peak I and Peak II of HDL Subfractions as Determined by Gradient Gel Electrophoresis

\begin{tabular}{|c|c|c|c|}
\hline & & Peak I & Peak II \\
\hline & & $d=1.063-1.125$ & $d=1.125-1.21$ \\
\hline \multirow{2}{*}{$\begin{array}{l}\text { Molecular } \\
\quad \text { diameter }(\AA)\end{array}$} & $\mathbf{B}^{*}$ & $105.5 \pm 2.1$ & $91.4 \pm 1.9$ \\
\hline & Ał & $100.9 \pm 1.6^{11}$ & $87.7 \pm 1.5 \S$ \\
\hline \multicolumn{4}{|l|}{ Molecular weight } \\
\hline (Daltons & B & $334 \pm 14$ & $233 \pm 15$ \\
\hline$\left.\times 10^{3}\right)$ & A & $303 \pm 11^{11}$ & $204 \pm 12 \S$ \\
\hline
\end{tabular}

* Before gemfibrozil therapy.

$\ddagger$ After gemfibrozil therapy.

$\S P<0.05$.

" $P<0.005 . n=6$, mean \pm SEM.

of cholesterol from LDL, so that the net effect on total sterol balance could be unchanged initially. Note that long-term effects of gemfibrozil on cholesterol balance could be quite different. In 254 patients treated for several years, LDL-C levels decreased by $23 \%$, whereas HDL-C levels remained elevated by $23 \%$ (1). Under these circumstances, total body cholesterol removal could be increased. Further research is clearly needed to clarify this point.

Since gemfibrozil is effective in a number of dyslipoproteinemic states, it is also possible that its effect on cholesterol balance may vary with the type of dyslipoproteinemia studied. Thus, it is important to characterize the patients and their disorders carefully before generalizations are drawn about gemfibrozil, apo A turnover, and sterol balance.

The significance of gemfibrozil in increasing apo A turnover is also related to the pathogenesis of cholelithiasis. Apo AI and apo AII are secreted in bile (67). Very recently, it was reported that apo AI and apo AII in supersaturated gallbladder bile inhibit the rate of formation of solid cholesterol crystals (68). This evidence suggests that the A apolipoproteins can prevent cholesterol gallstone formation. Thus, by increasing the turnover of A apolipoproteins, any lithogenic effect of gemfibrozil will be countered by an expected increased apo AI and apo AII biliary excretion. Such a protective action on gallstone formation may not occur from administration of drugs that increase plasma apo AI and AII apo levels by decreasing their removal rates.

Gemfibrozil and triglyceride metabolism. The data in this study demonstrate that in our patients, gemfibrozil not only decreased total plasma TG but also resulted in TRL that had a decreased ratio of apo $\mathrm{CIII}_{0}$ /apo $\mathrm{CII}$, apo $\mathrm{CIII}_{1} /$ apo $\mathrm{CII}$, and total apo CIII/apo CII ratio (Table VII). TRL size after

Table VII. Effects of Gemfibrozil on the Ratio of Apo CIII and its Subspecies to Apo CII in TRL

\begin{tabular}{lllll}
\hline & Apo Cllo/apo CII & Apo ClII/apo CII & Apo ClI $/$ /apo CII & Total apo CIII/apo CII \\
\hline B* & $0.26 \pm 0.06$ & $2.26 \pm 0.26$ & $2.14 \pm 0.34$ & $4.65 \pm 0.57$ \\
A & $0.19 \pm 0.07$ & $1.67 \pm 0.18$ & $1.65 \pm 0.3$ & $3.50 \pm 0.51$ \\
Paired $t$ test (B vs. A) & $P=0.013$ & $P=0.018$ & NS & $P=0.037$
\end{tabular}

* Before gemfibrozil therapy. $¥$ After gemfibrozil therapy. $n=6$, mean \pm SEM. 
Table VIII. Effects of Gemfibrozil on Postheparin Total, Extrahepatic Lipoprotein Lipase, and Hepatic Triglyceride Lipase

\begin{tabular}{|c|c|c|c|c|c|c|}
\hline \multirow[b]{2}{*}{ Subject } & \multicolumn{2}{|l|}{ Total } & \multicolumn{2}{|l|}{ LPL } & \multicolumn{2}{|l|}{ HTGL } \\
\hline & $\mathbf{B}^{*}$ & A $\ddagger$ & B & A & B & A \\
\hline & \multicolumn{6}{|c|}{ umol free fatty acid/h/ml } \\
\hline 1 & 36.1 & 34.1 & 17.3 & 18.6 & 18.8 & 15.4 \\
\hline 2 & 50.3 & 54.3 & 20.1 & 26.5 & 30.2 & 27.8 \\
\hline 3 & 37.5 & 38.3 & 21.7 & 23.4 & 15.8 & 14.9 \\
\hline 4 & 49.0 & 53.2 & 18.8 & 21.7 & 30.2 & 31.5 \\
\hline 5 & 39.1 & 42.3 & 12.1 & 21.5 & 27.0 & 20.8 \\
\hline 6 & 35.2 & 42.6 & 25.4 & 27.3 & 9.8 & 15.3 \\
\hline Mean \pm SEM & $41.2 \pm 2.7$ & $44.1 \pm 3.3$ & $19.2 \pm 1.8$ & $23.2 \pm 1.3$ & $22.0 \pm 3.4$ & $21.0 \pm 2.9$ \\
\hline Paired $t$ test (B vs. A) & $P=0.079$ & & $P=0.032$ & & NS & \\
\hline
\end{tabular}

* Before gemfibrozil therapy; $\ddagger$ after gemfibrozil therapy.

gemfibrozil was reduced in the majority of patients as indicated by a drop in the ratio of TRL core (TG + CE) to surface (protein + FC + PL) constituents (Table V).

Two approaches were undertaken to determine the mech- anism responsible for the TG lowering effect of gemfibrozil. In the first approach, postheparin lipolytic activity before and after gemfibrozil was measured. An increase in LPL activity was found in each patient (Table VIII). Since the initial

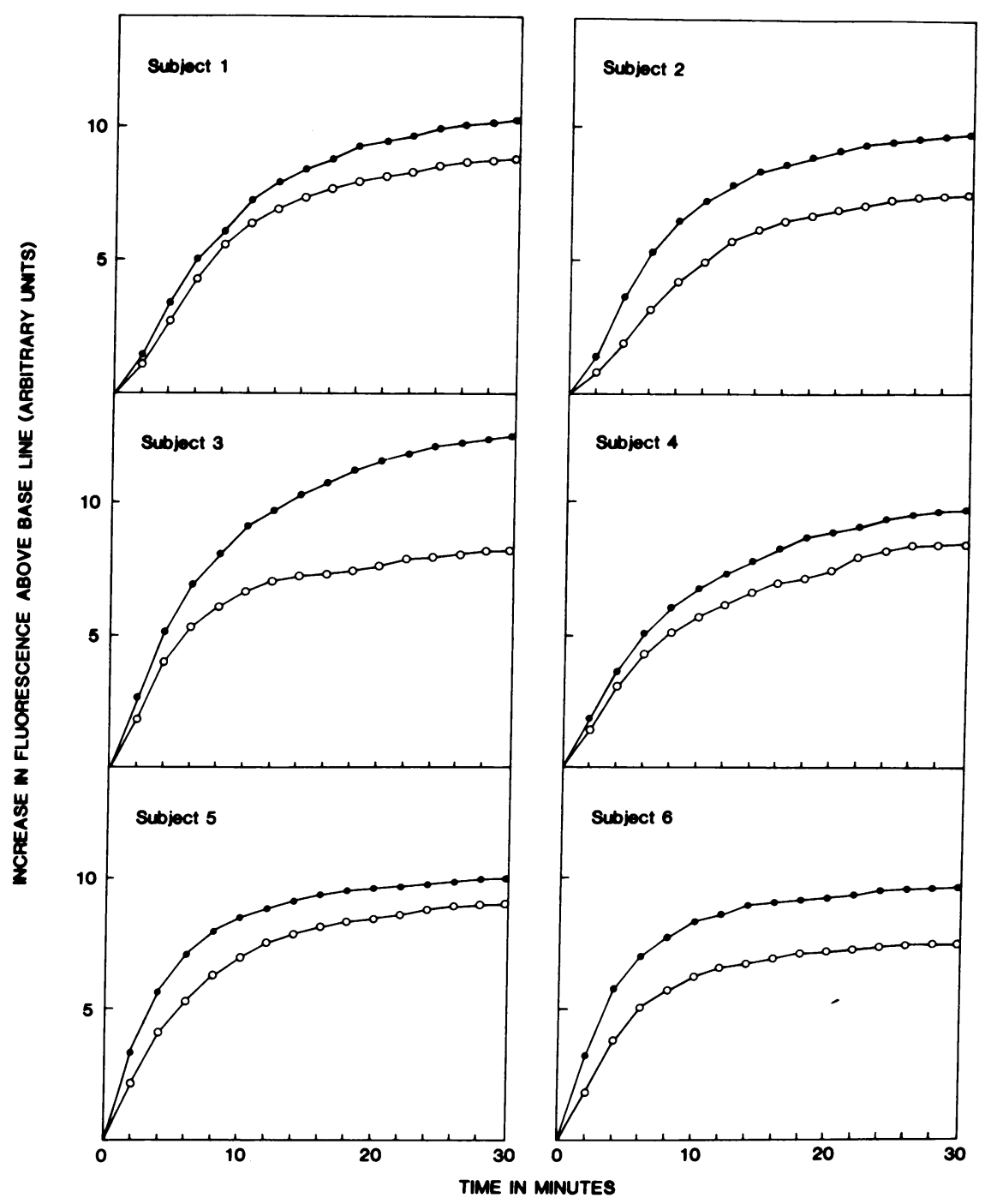

Figure 3. TRL lipolysis in vitro with bovine milk LPL. TRL was isolated from each patient by ultracentrifugation $(d<1.02 \mathrm{~g} / \mathrm{ml})$ before (一- - week 12) and after (-o-, week 22) gemfibrozil therapy. TRL were labeled with dansyl, 5-dimethylaminoaphthalene-1 sulfonyl phosphatidylethanolamine (DPE), DPE/TG $=1: 40$. A mixture of a constant mass $(600 \mu \mathrm{g})$ of TRL-TG in $50 \mathrm{mM}$ Tris- $\mathrm{HCl}, 0.9 \% \mathrm{NaCl}$ pH 7.6 in fatty acid free BSA was monitored continuously after addition of a fixed mass of LPL for increase in fluorescence at $37^{\circ} \mathrm{C}$ against time according to Johnson et al. (40, $41)$ as described previously $(32,42,43)$. 

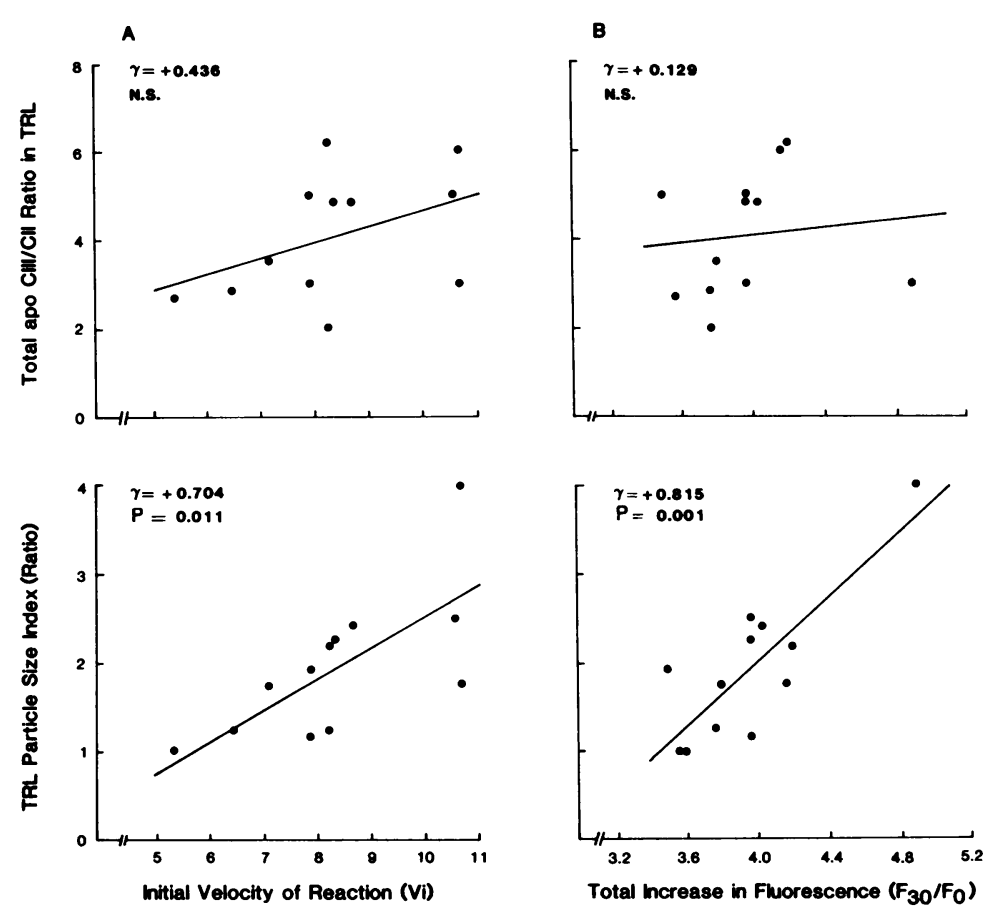

Figure 4. $(A)$ Correlations between TRL total apo CIII/apo CII ratio, TRL particle size index, and initial velocity of reaction (Vi). (B) Correlations between TRL total apo CIII/ apo CII ratio, TRL particle size index, and total increase in fluorescence (F30/F0). Vi and F30/F0 were TRL lipolytic kinetic parameters in vitro as described under Methods.

catabolism of TG rich particles is mediated by LPL, this data is consistent with the conclusion that gemfibrozil accelerated the catabolism of TG in these patients. These results are in accord with those of Nikkila et al. (7), who also found a mean increase $(+18.1 \%)$ of postheparin LPL in 20 subjects with type IV hypertriglyceridemia. These patients were clinically different from those in our study in that they were mostly obese subjects and were not known to have fasting chylomicronemia. This mechanism of action (via LPL) of gemfibrozil in lowering TG in hypertriglyceridemic patients is in addition to previous reports (11) and one recent study (12) that gemfibrozil decreases the synthesis of VLDL-apo B and TG, respectively. A very recent study on turnover of VLDL TG also showed that its FCR is increased by gemfibrozil (12).

In the second approach to assess gemfibrozil's mechanism of action, TRL isolated from each patient after gemfibrozil treatment was incubated in vitro with purified bovine LPL to assess the property of TRL as a substrate of LPL. This lipolytic assay, using a fluorescence probe for measuring the initial velocity of catalysis ( $\mathrm{Vi})$ and the extent of catabolism (F30/ F0), has been thoroughly validated previously by Johnson et al. $(40,41)$. The lipolytic rate (Vi) and extent of lipolysis (F30/ F0) was diminished in each patient studied (Fig. 3). Superficially, this data would appear inconsistent with the observed fall in apo CIII/apo CII ratio in postgemfibrozil TRL, since apo CIII has been reported to inhibit apo CII activation of LPL (69, 70) and a decrease in the VLDL apo CIII/apo CII ratio is associated with dietary treatment of hypertriglyceridemic subjects also (71). As background, it should be pointed out that studies showing the inhibitory properties of apo CIII are limited to use of emulsified artificial substrates and not TRL particles isolated from human subjects $(69,70)$. In addition to apo composition, VLDL size is an important determinant of its catabolism in vivo (72) and in vitro (73). The data in this study indicate a significant positive correlation between TRL size index and TRL catabolic velocity (Vi), and F30/F0, which represents the extent of TRL catabolism (bottom, Fig. 4).
Thus, size was an important determinant of TRL catabolism by LPL, but not TRL apo CIII/CII ratio, which did not correlate significantly with the parameters of lipolysis (top, Fig. 4). When the data for particle size was corrected by analysis of covariance, $\mathrm{Vi}$ of postgemfibrozil TRL remained significantly lower. The exact explanation of this observation is not clear. Since gemfibrozil decreases VLDL TG and apo B synthesis $(11,12)$, it is possible that it also alters the property of VLDL as a substrate for LPL. Future experiments using TRL subfractions of equal size are necessary to confirm this finding. Thus, the evidence so far indicates that the major mechanisms by which gemfibrozil lowers plasma TG levels are by decreasing VLDL synthesis and by increasing TRL catabolism by stimulating LPL. Apo CIII and apo CII changes may not be important in its TG lowering effect.

In summary, in patients with HDL deficiency associated with familial hypertriglyceridemia, we have documented increased turnover of apo AI and apo AII, the major proteins of HDL, resulting from gemfibrozil, the only drug known to have this effect at present. Additional research is necessary to determine whether drug-induced increased apo A turnover is associated with increased reverse cholesterol transport and/or protection from cholesterol gallstones.

\section{Acknowledgments}

We thank Dr. Richard L. Jackson and Dr. M. T. Ravi Subbiah for their constructive comments; Dr. J. David Johnson, Dr. Charles J. Glueck, and Dr. Harry R. Maxon for allowing us to use their facilities for part of this study; the Core Laboratory of the Cincinnati Lipid Research Clinic for lipid quantification; Ms. Evelyn Orso, Phyllis Downey, Barbara Liscow, and Wilma Roll for secretarial assistance; Elizabeth Hogg and Charalee Allen for preparation of the patients' diets; Peggy Hunt and the nursing staff of the Clinical Research Center; Trent Tracy, John Montag, Helen Crothers, and staff of the Lipid Clinic of the University of Cincinnati Medical Center.

This research was supported by the General Clinical Research Center Program of the Division of Research Resources, National 
Institutes of Health (NIH RR 00068-15), and by a research grant from the Warner-Lambert/Parke Davis Co.

\section{References}

1. Manninen, V., M. Malkonen, A. Eisalo, J. Virtamo, J. Tuomilehto, and P. Kuusisto. 1982. Gemfibrozil in the treatment of dyslipidaemia. A 5-year follow-up study. Acta. Med. Scand. 668(Suppl.):8287.

2. Lewis, J. E. 1982. Long-term use of gemfibrozil (Lopid) in the treatment of dyslipidemia. Angiology. 33:603-612.

3. Fenderson, R. W., S. Deutsch, E. Menachemi, B. Chin, and P. Samuel. 1982. Effect of gemfibrozil on serum lipids in man. Angiology. 33:581-593.

4. Eisalo, A., and V. Manninen. 1976. A long term trial of gemfibrozil in the treatment of hyperlipidemias. Proc. Roy. Soc. Med. 69(Suppl 2):49-52.

5. Nash, D. T. 1982. Hyperlipoproteinemia, atherosclerosis and gemfibrozil. Angiology. 33:594-602.

6. Olsson, A. G., S. Rossner, G. Walldius, and L. A. Carlson. 1976 Effect of gemfibrozil on lipoprotein concentrations in different types of hyperlipoproteinaemia. Proc. Roy. Soc. Med. 69(Suppl 2):28-31.

7. Nikkila, E. A., R. Ylikahri, and J. K. Huttunen. 1976. Gemfibrozil: effect on serum lipids, lipoproteins, post heparin plasma lipase activities and glucose tolerance in primary hypertriglyceriaemia. Proc. Roy. Soc. Med. 69(Suppl 2):58-63.

8. Konttinen, A., I. Kuisma, R. Ralli, S. Pohjola, and K. Ojala. 1979. The effect of gemfibrozil on serum lipids in diabetic patients. Ann. Clin. Res. 11:240-245.

9. Eisalo, A., V. Manninen, M. Malkonen, and B. Kuhlback. 1976. Hypolipidaemic action of gemfibrozil in adult nephrotics. Proc. Roy. Soc. Med. 69(Suppl 2):47-48.

10. Kashyap, M. L. 1984. The effect of gemfibrozil on plasma lipids and lipoproteins in man. Vasc. Med. 2:16-21.

11. Kissebah, A. H., S. Alfarsi, P. W. Adams, M. Seed, J. Folkard, and V. Wynn. 1976. Transport kinetics of plasma free fatty acid, very low density lipoprotein triglycerides and apoprotein in patients with endogenous hypertriglyceridaemia. Effect of 2,2-dimethyl,5(2,5-xylyloxy)valeric acid therapy. Atherosclerosis. 24:199-218.

12. Kesaniemi, Y. A., and S. M. Grundy. 1984. Influence of gemfibrozil and clofibrate on metabolism of cholesterol and plasma triglycerides in man. JAMA. 251:2241-2246.

13. Glomset, J. A. 1968. The plasma lecithin:cholesterol acyltransferase reaction. J. Lipid Res. 9:155-167.

14. Fielding, C. J., and P. E. Fielding. 1982. Cholesterol transport between cells and body fluids. Med. Clin. N. Am. 66:363-373.

15. Schwartz, C. C., L. G. Halloran, Z. R. Vlahcevic, D. H. Gregory, and L. Swell. 1978. Preferential utilization of free cholesterol from high-density lipoproteins for biliary cholesterol secretion in man. Science (Wash. DC). 200:62-64.

16. Lipid Research Clinics Program. 1984. The lipid research clinics coronary primary prevention trial results. I. Reduction in incidence of coronary heart disease. JAMA. 251:351-364.

17. Lipid Research Clinics Program. 1984. The lipid research clinics coronary primary prevention trial results. II. The relationship of reduction in incidence of coronary heart disease to cholesterol lowering. JAMA. 251:365-374.

18. Levy, R. I., J. F. Brensike, S. E. Epstein, S. F. Kelsey, E. R. Passamani, J. M. Richardson, I. K. Loh, N. J. Stone, R. F. Aldrich, J. W. Battaglini, D. J. Moriarity, and K. M. Detre. 1984. The influence of changes in lipid values induced by cholestyramine and diet on progression of coronary disease: results of the NHLBI Type II Coronary Intervention Study. Circulation. 69:325-337.

19. Brensike, J. F., R. I. Levy, S. F. Kelsey, E. R. Passamani, J. M. Richardson, I. K. Loh, N. J. Stone, R. F. Aldrich, J. W. Battaglini, D. J. Moriarty, M. R. Fisher, L. Friedman, W. Friedwald, K. M. Detre, and S. E. Epstein. 1984. Effects of therapy with cholestyramine on progression of coronary atherosclerosis: results of the NHLBI Type II Coronary Intervention Study. Circulation. 69:313324.

20. Lipid Research Clinics Population Studies Data Book. 1980 The prevalence study. United States Department of Health and Human Services, Public Health Service, National Institutes of Health. NIH Publication No. 80-1527.

21. Lipid Research Clinics Program. 1974. National Institutes of Health, Education and Welfare. Publication No. (NIH) 75-628:9-50.

22. United States Department of Health and Human Services. 1981. Diet 5 for dietary management of mixed hyperglyceridemia (type V hyperlipoproteinemia). National Institutes of Health Publication No. 81-115:1-10.

23. Kashyap, M. L., R. L. Barnhart, L. S. Srivastava, G. Perisutti, P. Vink, C. Allen, E. Hogg, D. Brady, C. J. Glueck, and R. L. Jackson. 1982. Effects of dietary carbohydrate and fat on plasma lipoproteins and apolipoproteins C-II and C-III in healthy men. J. Lipid Res. 23: 877-886.

24. Roeschlau, P., E. Bernt, and W. Gruber. 1974. Enzymatic determination of total cholesterol in serum. Z. Klin. Chem. Klin. Biochem. 12:226.

25. Bartlett, G. R. 1959. Phosphorous assay in column chromatography. J. Biol. Chem. 234:466-468.

26. Lowry, O. H., N. J. Rosebrough, A. L. Farr, and R. J. Randall. 1951. Protein measurement with the folin phenol reagent. J. Biol. Chem. 193:265-275.

27. Kashyap, M. L., B. A. Hynd, and K. Robinson. 1980. A rapid and simple method for measurement of total protein in very low density lipoproteins by the Lowry assay. J. Lipid Res. 21:491-495.

28. Havel, R. J., H. A. Eder, and J. H. Bragdon. 1955. The distribution and chemical composition of ultracentrifugally separated lipoproteins in human serum. J. Clin. Invest. 34:1345-1353.

29. McFarlane, A. J. 1958. Efficient trace labeling of proteins with iodine. Nature (Lond.). 183:53.

30. Bilheimer, D. W., S. Eisenberg, and R. I. Levy. 1972. The metabolism of very low density lipoprotein proteins. Biochim. Biophys. Acta. 260:212-221.

31. Saku, K., G. S. Reddy, B. A. Hynd, and M. L. Kashyap. 1984. Renal handling of high density lipoproteins by isolated perfused kidneys. Metab. Clin. Exp. 33:432-438.

32. Saku, K., C. Cedres, B. McDonald, B. A. Hynd, B. W. Liu, L. S. Srivastava, and M. L. Kashyap. 1984. CII anapolipoproteinemia and severe hypertriglyceridemia. Report of a rare case with absence of $\mathrm{CII}$ apolipoprotein isoforms and review of literature. Am. J. Med. 77: 457-462.

33. Laurell, C. B. 1966. Quantitative estimation of proteins by electrophoresis in agarose gel containing antibodies. Anal. Biochem. 15:45-52.

34. Mendoza, S. G., A. Zerpa, H. Carrasco, O. Colmenares, A Rangel, P. S. Gartside, and M. L. Kashyap. 1983. Estradiol, testosterone, apolipoproteins, lipoprotein cholesterol, and lipolytic enzymes in men with premature myocardial infarction and angiographically assessed coronary occlusion. Artery. 12:1-23.

35. Fidge, N., P. Nestel, T. Ishikawa, M. Reardon, and T. Billington. 1980. Turnover of apoproteins A-I and A-II of high density lipoprotein and the relationship to other lipoproteins in normal and hyperlipidemic individuals. Metab. Clin. Exp. 29:643-653.

36. Weber, K., and M. Osborn. 1975. Proteins and sodium dodecyl sulfate: molecular weight determination on polyacrylamide gels and related procedures. In The Proteins. H. Neurath, and R. L. Hill, editors. Academic Press, Inc., New York. 168-233.

37. Kashyap, M. L., B. A. Hynd, K. Robinson, and P. S. Gartside. 1981. Abnormal preponderance of sialylated apolipoprotein CIII in triglyceride rich lipoproteins in type B hyperlipoproteinemia. Metab. Clin. Exp. 30:111-118.

38. Krauss, R. M., R. I. Levy, and D. S. Fredrickson. 1974. Selective measurement of two lipase activities in postheparin plasma 
from normal subjects and patients with hyperlipoproteinemia. J. Clin. Invest. 54:1107-1124.

39. Huttunen, J. K., C. Ehnholm, M. Kekki, and E. A. Nikkila. 1976. Post heparin plasma lipoprotein lipase and hepatic lipase in normal subjects and in patient with hypertriglyceridemia: correlations to sex, age and various parameters of triglyceride metabolism. Clin. Sci. Mol. Med. 50:249-260.

40. Johnson, J. D., M. R. Taskinen, N. Matsuoka, and R. L. Jackson. 1980. Dansyl phosphatidylethanolamine-labeled very low density lipoproteins. A fluorescent probe for monitoring lipolysis. $J$. Biol. Chem. 255:3461-3465.

41. Johnson, J. D., M. R. Taskinen, N. Matsuoka, and R. L. Jackson. 1980. On the mechanism of the lipoprotein lipase-induced fluorescence changes in dansyl phosphatidylethanolamine-labeled very low density lipoproteins. J. Biol. Chem. 255:3466-3471.

42. Matsuoka, M., K. Shirai, J. D. Johnson, M. L. Kashyap, L. S. Srivastava, T. Yamamura, A. Yamamoto, Y. Saito, A. Kumagai, and R. L. Jackson. 1981. Effects of apolipoprotein C-II (apo C-II) on the lipolysis of very low density lipoproteins from apo C-II deficient patients. Metab. Clin. Exp. 30:818-824.

43. Taskinen, M. R., J. D. Johnson, M. L. Kashyap, K. Shirai, C. J. Glueck, and R. L. Jackson. 1981. Catabolism of human very low density lipoproteins in vitro: a fluorescent phospholipid method for monitoring lipolysis. J. Lipid Res. 22:382-386.

44. Anderson, D. W., A. V. Nichols, T. M. Forte, and F. T. Lindgren. 1977. Particle distributions of human serum high density lipoprotein. Biochim. Biophys. Acta. 493:55-68.

45. Kashyap, M. L., R. L. Barnhart, L. S. Srivastava, G. Perisutti, C. Allen, E. Hogg, C. J. Glueck, and R. L. Jackson. 1983. Alimentary lipemia: plasma high density lipoproteins and apolipoproteins $\mathrm{CII}$ and CIII in healthy subjects. Am. J. Clin. Nutr. 37:233-243.

46. Blanche, P. J., E. L. Gong, T. M. Forte, and A. V. Nichols. 1981. Characterization of human high-density lipoproteins by gradient gel electrophoresis. Biochim. Biophys. Acta. 664:408-419.

47. Ostle, B., and R. W. Mensing. 1975. Statistics in research. Iowa State University Press, Ames, IA. Third ed. 208-214.

48. Schaefer, E. J., L. A. Zech, L. L. Jenkins, T. J. Bronzert, E. A Rubalcaba, F. T. Lindgren, R. L. Aamodt, and H. B. Brewer, Jr. 1982. Human apolipoprotein A-I and A-II metabolism. J. Lipid Res. 23: $850-862$.

49. Berson, S. A., and R. S. Yalow. 1957. Distribution of metabolism of ${ }^{131}$ I-labeled proteins in man. Fed. Proc. 16:13S

50. Snedecor, G. R., and W. G. Cochran. 1967. Statistical methods. Iowa State University Press, Ames, IA. Sixth ed. 135-198.

51. Sata, T., R. J. Havel, and A. L. Jones. 1972. Characterization of subfractions of triglyceride-rich lipoproteins separated by gel chromatography from blood plasma of normolipemic and hyperlipemic humans. J. Lipid Res. 13:757-768.

52. Felker, T. E., M. Fainaru, R. L. Hamilton, and R. J. Havel. 1977. Secretion of arginine-rich and A-I apolipoproteins by the isolated perfused rat liver. J. Lipid Res. 18:465-473.

53. Imaizumi, K., M. Fainaru, and R. J. Havel. 1978. Composition of protein of mesenteric lymph chylomicrons in the rat and alterations produced upon exposure of chylomicrons to blood serum and serum proteins. J. Lipid Res. 19:712-722.

54. Marsh, J. B. 1976. Apolipoproteins of the lipoproteins in a nonrecirculating perfusate of rat liver. J. Lipid Res. 17:85-90.

55. Wu, A. L., and H. G. Windmueller. 1979. Relative contributions by liver and intestine to individual plasma polipoproteins in the rat. J. Biol. Chem. 254:7316-7322.

56. Havel, R. J., J. P. Kane, and M. L. Kashyap. 1973. Interchange of apolipoproteins between chylomicrons and high density lipoprotein during alimentary lipemia in man. J. Clin. Invest. 52:32-38.

57. Taskinen, M. R., M. L. Kashyap, L. S. Srivastava, M. Ashraf, J. D. Johnson, G. Perisutti, D. Brady, C. J. Glueck, and R. L. Jackson. 1982. In vitro catabolism of human plasma very low density lipoproteins. Atherosclerosis. 41:381-394.

58. Fielding, C. J., and P. E. Fielding. 1981. Evidence for a lipoprotein carrier in human plasma catalyzing sterol efflux from cultured fibrobrasts and its relationship to lecithin:cholesterol acyltransferase. Proc. Natl. Acad. Sci. USA. 78:3911-3914.

59. Fielding, C. J., and P. E. Fielding. 1971. Purification and substrate specificity of lecithin-cholesterol acyltransferase from human plasma. FEBS (Fed. Eur. Biochem. Soc.) Lett. 15:355-358.

60. Soutar, A. K., C. W. Garner, H. N. Baker, J. T. Sparrow, R. L. Jackson, A. M. Gotto, and L. C. Smith. 1975. Effects of the human plasma apolipoproteins and phosphatidylcholine acyl donor on the activity of lecithin:cholesterol acyltransferase. Biochemistry. 14: 3057-3064.

61. Shepherd, J., C. J. Pakcard, J. R. Patsch, A. M. Gotto, and O. D. Taunton. 1979. Effects of nicotinic acid therapy on plasma high density lipoprotein subfraction distribution and composition and on apolipoprotein A metabolism. J. Clin. Invest. 63:858-867.

62. Carlson, L. A., A. G. Olsson, and D. Ballantyne. 1977. On the rise in low density and high density lipoproteins in response to the treatment of hypertriglyceridemia in type IV and type V hyperlipoproteinaemias. Atherosclerosis. 26:603-609.

63. Packard, C. J., J. M. Stewart, J. L. H. C. Third, H. G. Morgan, T. D. Veitch Lawrie, and J. Shepherd. 1980. Effects of nicotinic acid therapy on high-density lipoprotein metabolism in type II and type IV hyperlipoproteinaemia. Biochim. Biophys. Acta. 618:53-62.

64. Blum, C. B., R. I. Levy, S. Eisenberg, M. Hall, R. H. Goebel, and M. Berman. 1977. High density lipoprotein metabolism in man. J. Clin. Invest. 60:795-807.

65. Grundy, S. M., H. Y. I. Mok, L. Zech, and M. Berman. 1981 Influence of nicotinic acid on metabolism of cholesterol and triglycerides in man. J. Lipid Res. 22:24-36.

66. Einarsson, K., K. Hellstrom, and B. Leijd. 1977. Bile acid kinetics and steroid balance during nicotinic acid therapy in patients with hyperlipoproteinemia types II and IV. J. Lab. Clin. Med. 90:613622 .

67. Sewell, R. B., S. J. T. Mao, T. Kawamoto, and N. F. LaRusso. 1983. Apolipoproteins of high, low, and very low density lipoproteins in human bile. J. Lipid Res. 24:391-401.

68. Kibe, A., R. T. Holzbach, N. F. LaRusso, and S. J. T. Mao. 1984. Inhibition of cholesterol crystal formation by apolipoproteins in supersaturated model bile. Science (Wash. DC). 255:514-516.

69. Brown, W. V., and M. L. Baginsky. 1972. Inhibition of lipoprotein lipase by an apoprotein of human very low density lipoprotein. Biochem. Biophys. Res. Commun. 46:375-382.

70. Ekman, R., and P. Nilsson-Ehle. 1975. Effects of apolipoproteins on lipoprotein lipase activity of human adipose tissue. Clin. Chim. Acta. 63:29-35.

71. Kashyap, M. L., B. A. Hynd, and W. C. Wilder. 1980. Effect of dietary therapy on apolipoprotein CIII and CII metabolism in type V hyperlipoproteinemia. Clin. Res. 28:396A. (Abstr.)

72. Streja, D. A. 1979. Triglyceride removal from very low density lipoproteins in vivo as a function of their triglyceride content. Atherosclerosis. 32:57-67.

73. Kashyap, M. L., M. R. Taskinen, B. A. Hynd, J. D. Johnson, D. W. Brady, and K. Robinson. 1979. Lipoprotein lipase activity is influenced by triglyceride rich lipoprotein particle size. Clin. Res. 27: 657A. (Abstr.) 